Elsevier

\title{
Developmental Changes in Taste Responses from Glossopharyngeal Nerve in Sheep and Comparisons with Chorda Tympani Responses
}

\author{
CHARLOTTE M. MISTRETTA* and ROBERT M. BRADLEY** \\ Department of Oral Biology, School of Dentistry, University of Michigan, Ann Arbor MI 48109 (U.S.A.)
}

(Accepted June 30th, 1983)

Key words: taste — development - glossopharyngeal nerve - chorda tympani nerve — taste bud

\begin{abstract}
To learn whether there are developmental changes in salt and acid taste responses from the posterior tongue, we recorded from the glossopharyngeal nerve, which innervates taste buds in circumvallate papillae, in sheep fetuses, lambs and adults. Multifiber responses to $\mathrm{NH}_{4} \mathrm{Cl}, \mathrm{KCl}, \mathrm{NaCl}, \mathrm{LiCl}$, citric and hydrochloric acids were expressed as ratios, relative to responses for two standard chemicals, $\mathrm{NH}_{4} \mathrm{Cl}$ and $\mathrm{KCl}$. Response ratios for $\mathrm{NaCl}$ and $\mathrm{LiCl}$, relative to either standard, increased during development, but the magnitude of the change was small. $\mathrm{KCl}$ elicited very large magnitude responses, relative to $\mathrm{NH}_{4} \mathrm{Cl}$, in the youngest fetuses, and then decreased by $50 \%$ in stimulating effectiveness. Relative responses to both acids also decreased developmentally. The general shapes of $\mathrm{KCl}$ response-concentration functions did not change throughout development; however, in the youngest fetuses, the $\mathrm{NH}_{4} \mathrm{Cl}_{\mathrm{re}}$ sponse-concentration function was not similar to that in older animals. These developmental changes are different than those for responses from anterior tongue taste buds recorded from the chorda tympani nerve. Anterior tongue responses to $\mathrm{NaCl}$ and $\mathrm{LiCl}$ change most substantially and those to $\mathrm{KCl}$ change very little; acid responses do not change. The developmental differences for anterior versus posterior tongue responses suggest that membrane composition and maturational changes of taste buds in the two locations are not the same. Response-concentration functions from both tongue areas support the proposition that specific membrane components interacting with various salts are added during development.
\end{abstract}

\section{INTRODUCTION}

During development there are substantial changes in neurophysiological responses from the chorda tympani nerve, which innervates taste buds on the anterior tongue ${ }^{13.16,17,25}$. In both rat and sheep, responses to $\mathrm{NaCl}$ and $\mathrm{LiCl}$ are of very small magnitude in early development and progressively increase relative to other salts, acids and sucrose. Thus, the typical, large magnitude response to $\mathrm{NaCl}$ and $\mathrm{LiCl}$ from the anterior tongue is not present during early formation of the taste system, but gradually appears throughout development.

When $\mathrm{NaCl}$ and $\mathrm{LiCl}$ are used to stimulate taste buds in circumvallate papillae on the posterior tongue of adult mammals, however, large magnitude responses are not generally elicited relative to other chemicals $1.14 .26 .29,30$. To attain these different adult response characteristics, a different set of devel- opmental changes might be expected from the posterior tongue. Therefore, to collect such comparative data, we recorded responses to salts and acids from the glossopharyngeal nerve, which innervates taste buds in circumvallate papillae, in sheep fetuses, lambs and adults. Chemical stimuli and experimental age groups were selected to permit direct comparison with chorda tympani nerve responses from taste buds on the anterior tongue 25 .

\section{METHODS}

\section{Animals and surgical preparation}

Sheep in 5 age groups were studied: (a) 110 days of gestation, included 10 fetuses aged 107-113 days of gestation (term $=147$ days); (b) 130 days of gestation, included 9 fetuses aged 126-132 days of gestation; (c) perinatal, 10 animals aged 142 days of gestation to 7 postnatal days; (d) lamb, 10 lambs aged

\footnotetext{
* Also from the Center for Human Growth and Development and the Center for Nursing Research, School of Nursing.

** Also from the Department of Physiology.
} 
33-86 days postnatal; (e) adult, 6 ewes aged 2-4 years. Adults and lambs were anesthetized with an intravenous injection of sodium pentobarbital (30 $\mathrm{mg} / \mathrm{kg}$ for adults; $20-25 \mathrm{mg} / \mathrm{kg}$ for lambs), were tracheotomized and given supplemental $\mathrm{O}_{2}(1.5-2.5$ liters/min). An indwelling catheter was placed in the jugular vein for subsequent anesthetic administration. Fetuses (anesthetized via the pregnant ewe) were delivered onto a table at the ewe's side, and wrapped with a heating pad ${ }^{11}$. The umbilical and placental circulation remained intact. Rectal temperature was monitored continuously.

\section{Electrophysiology}

The fetal, lamb or adult mouth was incised to expose the entire, lateral field of 20-30 circumvallate papillae for stimulation on the recording side. The animal's head was then positioned in a holder, and the glossopharyngeal nerve was dissected by a lateral approach through the cheek and angle of the mandible. The glossopharyngeal was located just beneath the hyoid bone, which was partially removed. The nerve was cut centrally, dissected, desheathed, and divided into small, naturally occurring bundles.

A discrete bundle of nerve fibers was placed on a platinum recording electrode with a reference electrode in nearby tissues. It was not possible to record from the entire glossopharyngeal nerve at once and obtain a good signal-to-noise ratio. Therefore responses were recorded systematically from each bundle of the nerve to ensure that activity from the entire population of posterior tongue taste buds was studied. Neural activity was recorded using a preamplifier, oscilloscope and audiomonitor, stored on magnetic tape, and then passed through a full-wave rectifier and smoothing circuit with a time constant of $0.5 s^{3}$. The integrated neural activity was monitored with a rectilinear pen recorder.

\section{Stimuli}

Taste stimuli were $0.5 \mathrm{M}$ solutions of reagent grade $\mathrm{NH}_{4} \mathrm{Cl}, \mathrm{KCl}, \mathrm{NaCl}$ and $\mathrm{LiCl}, 0.1 \mathrm{M}$ citric acid and $0.01 \mathrm{~N} \mathrm{HCl}$, dissolved in distilled water. Concentration series $(0.10-1.00 \mathrm{M})$ of $\mathrm{NH}_{4} \mathrm{Cl}$ and $\mathrm{KCl}$ were also used. It was essential to warm stimuli to tongue surface temperature $\left(38.5^{\circ} \mathrm{C}\right)$ to obtain stable neurophysiological responses. Room temperature stimuli cooled the tongue and elicited temperature re- sponses ${ }^{26.29 .30}$; these responses changed as the solutions gradually warmed to tongue temperature and therefore produced a fluctuating baseline.

Salt stimuli were applied before acids but the order of salt stimulation was varied. One salt (either $\mathrm{NH}_{4} \mathrm{Cl}$ or $\mathrm{KCl}$ ) was applied periodically to monitor response reproducibility. If responses to these repeated stimuli varied by more than $15 \%$, data were not included for analysis. All stimuli were applied at least twice

Twenty ml of each stimulus were flowed on the entire field of circumvallate papillae from syringes. Taste responses were readily elicited in this manner and no additional procedures were needed for stimulation. After $20-40 \mathrm{~s}$, the stimulus was rinsed from the tongue with distilled water $\left(38.5^{\circ} \mathrm{C}\right)$. At least $40 \mathrm{~s}$ then elapsed before application of another stimulus.

\section{Data analysis}

Integrated records of multifiber glossopharyngeal nerve responses were composed of an initial phasic component that gradually adapted to a lower magnitude of neural response. The magnitude of the phasic component is related to stimulus application duration and flow rate 21.27 , to the tactile component of stimulus application, and to the chemical stimulus per se. The tactile response from the glossopharyngeal nerve is especially large, as others have described 1.6.7.18; therefore to exclude that portion of the response related to variables other than taste, we measured responses at $20 \mathrm{~s}$ after stimulus onset. This enabled us to compare our data directly with responses from anterior tongue 25 and with published data on taste responses from adults of other species $4.5,13.16$.

In order to compare integrated response magnitudes among different animals, it is essential to calculate relative response ratios for each experiment rather than use comparisons of absolute response magnitudes ${ }^{4}$. For each animal, we calculated the ratio of every response relative to a 'standard' response. Therefore, a response equal to that elicited during stimulation of the tongue with the standard would have a ratio of 1.00 .

Ideally, the standard, reference chemical should be that stimulus which does not elicit changing response magnitudes but which does elicit substantial response magnitudes across all groups. Visual in- 
spection of data indicated that $\mathrm{NH}_{4} \mathrm{Cl}$ was the best choice and it permitted direct comparisons with published chorda tympani responses 25 . However, since use of a standard chemical makes it impossible to draw conclusions about the standard chemical per se, we also used a second standard, $\mathrm{KCl}$. Response ratios for repeated applications of chemicals and for separate glossopharyngeal nerve bundles were averaged for each animal. Then ratios were compared among animals.

\section{Histology}

Circumvallate papillae from 4 fetuses at 110 days of gestation and 4 adults were prepared for scanning electron or light microscopy. Fetuses were perfused through the heart and adults through the carotid arteries with Karnovsky's formaldehyde-glutaraldehyde fixative buffered with sodium cacodylate. Several individual circumvallate papillae were dissected from the tongue and post-fixed. For light microscopy, tissues were embedded in paraffin, serially sectioned at
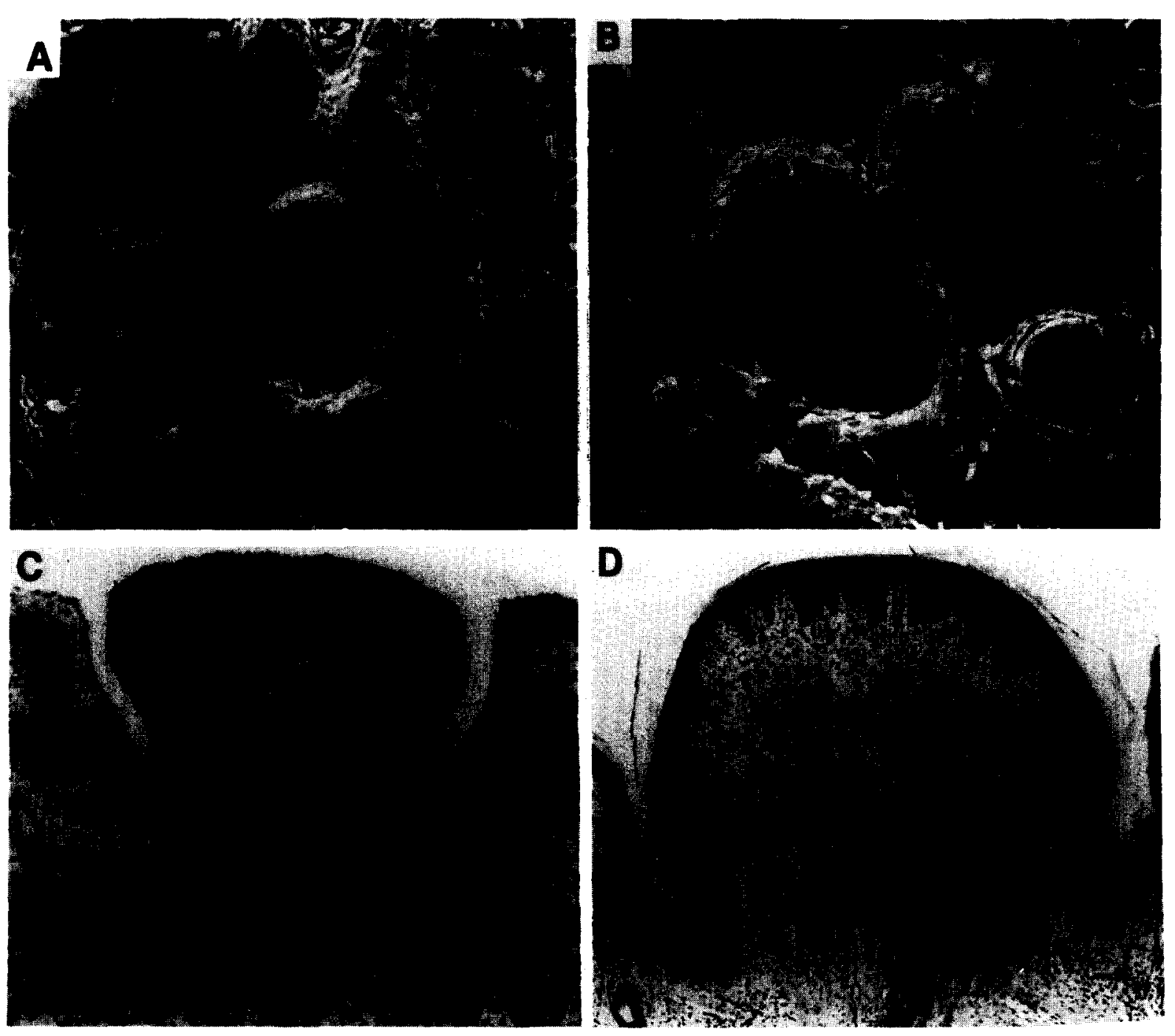

Fig. 1. A and B: scanning electron micrographs of circumvallate papillae from the posterior tongue of fetuses at 110 days of gestation $(100 \times)$. Various papilla shapes are observed and frequently more than one papilla share a lateral wall. C: light micrograph of a circumvallate papilla from a 110-day fetus $(250 \times)$. Taste buds are apparent on the superficial and lateral walls of the papilla. Von Ebner's glands are present at the papilla base. D: light micrograph of a papilla from an adult sheep $(50 \times)$. Taste buds are found in the lateral papilla walls only. 
$15 \mu \mathrm{m}$ and stained with hematoxylin and eosin. For scanning electron microscopy, tissues were dehydrated in ethanol, prepared with critical point drying, and coated with gold palladium.

\section{RESULTS}

\section{Posterior tongue taste buds}

Taste buds are located in 20-30 circumvallate papillae on each lateral edge of the posterior tongue in sheep. Foliate papillae are not observed in sheep or in cow, another ruminant ${ }^{8,12}$. The circumvallate papillae are of various shapes and often more than one papilla apparently share a surrounding epithelial wall (Fig. 1A and B). At 110 days of gestation the papillae and associated von Ebner's glands are well-developed (Fig. 1C). Taste buds in fetuses and older animals are found in the wall of the papilla only, not in the adjacent epithelial wall. About 45-80 taste buds are found per papilla in the 110 day fetus, and some of these buds are located in the superficial epithelium covering the papilla (Fig. 1C). In adults, 50-200 taste buds are found per papilla, located in the lateral epithelium only (Fig. 1D). Therefore, the total number of posterior tongue taste buds increases from fetal to adult ages.

\section{Responses to $0.5 \mathrm{M}$ salts}

Integrated responses from one animal in each age group illustrate general neurophysiological response characteristics (Fig. 2). $\mathrm{NaCl}$ and $\mathrm{LiCl}$ elicited the smallest response magnitudes throughout development compared to $\mathrm{NH}_{4} \mathrm{Cl}$ or $\mathrm{KCl}$. $\mathrm{KCl}$ elicited a very large response in 110 days fetuses and was the most effective salt stimulus at this age. The maximum effectiveness of $\mathrm{KCl}$ as a salt stimulus at 110 days was consistent throughout all nerve bundles and fetuses studied, except in one fetus with a large $\mathrm{NH}_{4} \mathrm{Cl}$ response that exceeded that of $\mathrm{KCl}$.

By 130 days of gestation, $\mathrm{KCl}$ and $\mathrm{NH}_{4} \mathrm{Cl}$ had reversed in order of stimulating effectiveness (Fig. 2). $\mathrm{NH}_{4} \mathrm{Cl}$ elicited the largest response and this order was maintained in perinatal animals, lambs and adults.

To quantify changes in salt taste responses, average ratios for each salt and age group were plotted (Fig. 3) and studied with analysis of variance. Relative to $\mathrm{NH}_{4} \mathrm{Cl}, \mathrm{KCl}$ decreased in effectiveness during development $\left(F_{4,44}=15.81, P<0.0001\right)$. The decrease was so substantial that $\mathrm{KCl}$, which was almost twice as effective as $\mathrm{NH}_{4} \mathrm{Cl}$ at 110 days, was about half as effective in lambs and adults. Pairwise comparisons between individual age groups (Scheffé allowances) indicated that the 110-day fetal ratio was different from every other group $(P<0.0001)$ and the
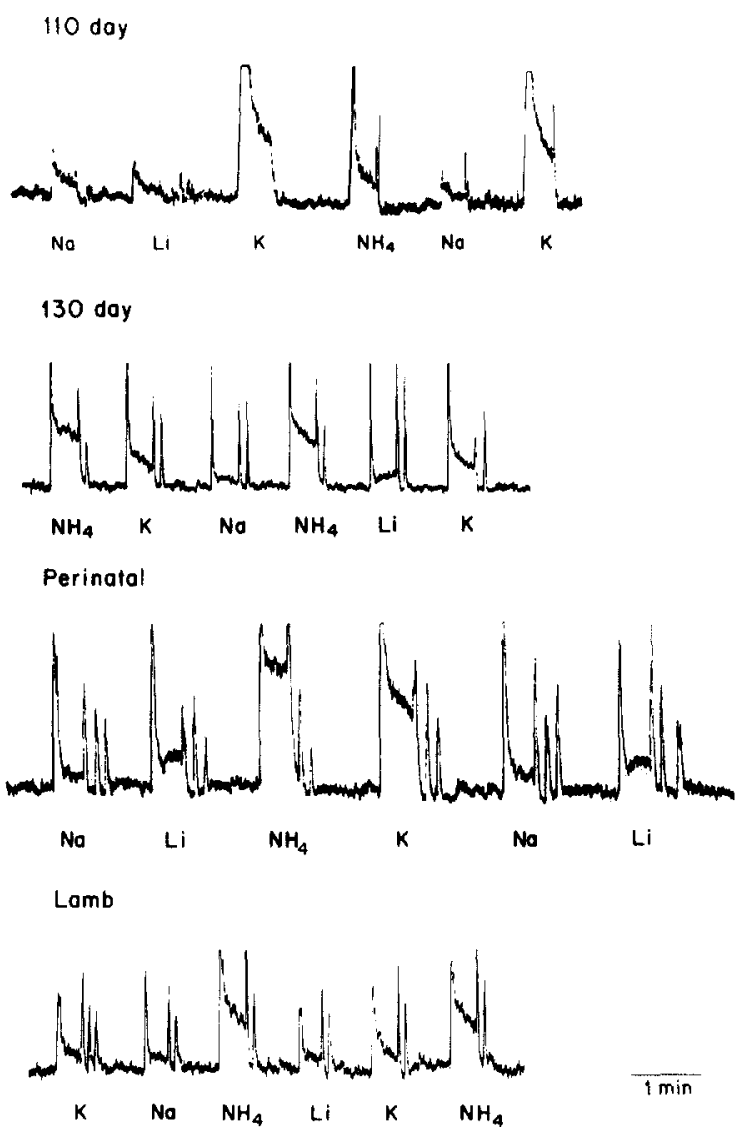

Adult

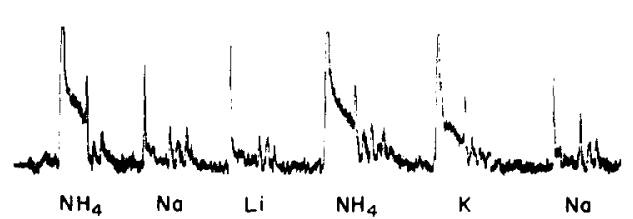

Fig. 2. Integrated records of multifiber responses from the glossopharyngeal nerve in an animal from each of the five age groups. Chemical stimuli applied to the posterior tongue were $0.5 \mathrm{M} \mathrm{NaCl}, \mathrm{LiCl}, \mathrm{KCl}$ and $\mathrm{NH}_{4} \mathrm{Cl}$. Although $\mathrm{KCl}$ was the most effective salt stimulus in fetuses at 110 days of gestation, $\mathrm{NH}_{4} \mathrm{Cl}$ was most effective in older fetuses, lambs and adults. Since the pen recorder gain was set to illustrate the relatively small magnitude responses to $\mathrm{NaCl}$ and $\mathrm{LiCl}$, in some records the early, transient portions of responses to $\mathrm{KCl}$ and $\mathrm{NH}_{4} \mathrm{Cl}$ are saturated. 
Glossopharyngeal
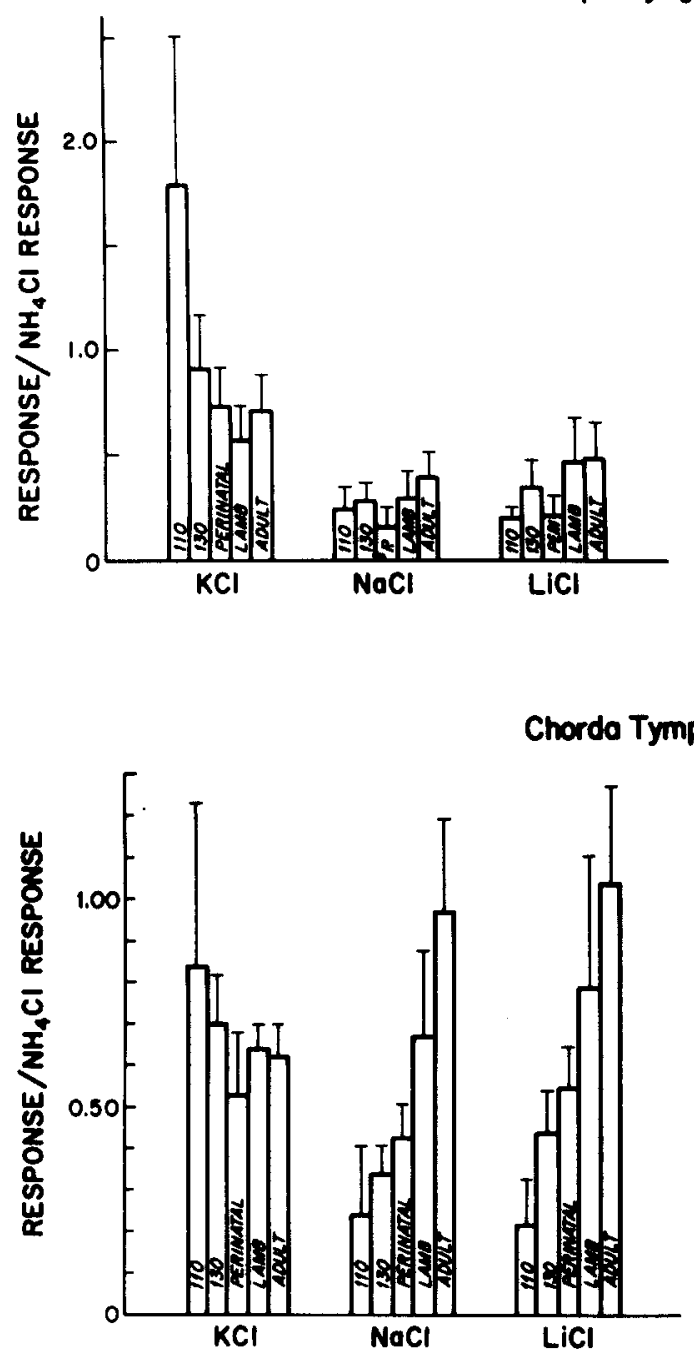

Fig. 3. Top: mean response ratios and standard deviations for $\mathrm{KCl}, \mathrm{NaCl}$ and $\mathrm{LiCl}$, relative to $\mathrm{NH}_{4} \mathrm{Cl}$, recorded from the glossopharyngeal nerve in fetuses (110 and 130 days of gestation, and perinatal), lambs and adults. For each salt, a response equal in magnitude to that elicited by $\mathrm{NH}_{4} \mathrm{Cl}$ yields a ratio of $1.00 . \mathrm{KCl}$ response ratios decrease substantially during development, whereas $\mathrm{NaCl}$ and $\mathrm{LiCl}$ ratios increase slightly. Bottom: data from a previous study on chorda tympani nerve responses ${ }^{25}$. When recording from the anterior tongue, $\mathrm{KCl}$ ratios decreased only slightly during development, whereas $\mathrm{NaCl}$ and $\mathrm{LiCl}$ ratios increased greatly. Note the differences in scales for glossopharyngeal and chorda tympani nerve response ratios.

130-day versus lamb groups were different $(P=$ 0.05 ). No other pairs of age groups were significantly different. Therefore the decrease in $\mathrm{KCl}$ response, relative to $\mathrm{NH}_{4} \mathrm{Cl}$, takes place prenatally and does not continue after birth.
There were also changes in responses to $\mathrm{NaCl}$ and $\mathrm{LiCl}$ (Fig. 3), which increased relative to $\mathrm{NH}_{4} \mathrm{Cl}$ $\left(\mathrm{NaCl}: F_{4,44}=4.20, P=0.006 ; \mathrm{LiCl}: F_{4,44}=7.18, P\right.$ $=0.0002$ ). Pairwise comparisons between groups for $\mathrm{NaCl}$ and $\mathrm{LiCl}$ indicated differences between some prenatal groups and between some postnatal groups (NaCl: 130-day versus perinatal; perinatal versus lamb and adult; lamb versus adult; $\mathrm{LiCl}: 110$ versus 130-day; 130-day versus perinatal; perinatal versus lamb and adult; all $P$ values $<0.05$ ). Therefore the increase in relative ratios apparently continues after birth.

Comparison of anterior and posterior tongue responses

In Fig. 3, the salt ratios for glossopharyngeal nerve responses are compared with those for chorda tympani nerve responses from anterior tongue taste buds reported in a previous study 25 . Whereas the greatest posterior tongue change is for $\mathrm{KCl} / \mathrm{NH}_{4} \mathrm{Cl}$ ratios, the $\mathrm{NaCl}$ and $\mathrm{LiCl} / \mathrm{NH}_{4} \mathrm{Cl}$ ratios alter most substantially for anterior tongue. Thus, developmental changes in salt responses for taste buds on front and back of tongue are different.

When chemical responses are calculated relative to a standard and a developmental change is observed, it is not clear whether the response to the standard, or to the other chemical is changing. Therefore, to learn whether use of another standard chemical would alter general conclusions, we recalculated salt ratios for both glossopharyngeal and chorda tympani nerves, relative to the $\mathrm{KCl}$ response (Fig. 4). The extent of increase in $\mathrm{NaCl}$ and $\mathrm{LiCl}$ responses from the glossopharyngeal nerve was enhanced, when compared to the $\mathrm{KCl}$ standard $(\mathrm{NaCl}$ : $F_{4,44}=9.52, \quad P<0.0001 ; \mathrm{LiCl}: F_{4,44}=14.92$, $P<0.0001)$. There was also an increase in $\mathrm{NH}_{4} \mathrm{Cl}$ responses from posterior tongue, relative to $\mathrm{KCl}$ $\left(F_{4.44}=9.96, P<0.0001\right)$. Pairwise comparisons between age groups for each of the 3 salts demonstrated a significant difference between the 110-day fetal and all other age groups, and also between lamb and perinatal or adult age groups $(P<0.05)$; therefore, postnatal changes occur as well as prenatal.

When chorda tympani salt responses were recalculated relative to $\mathrm{KCl}$ (Fig. 4), significant increases in $\mathrm{NaCl}\left(F_{4,41}=22.21, P<0.0001\right)$ and $\mathrm{LiCl}\left(F_{4,41}=\right.$ $19.56, P<0.0001)$ ratios were still observed, as they 

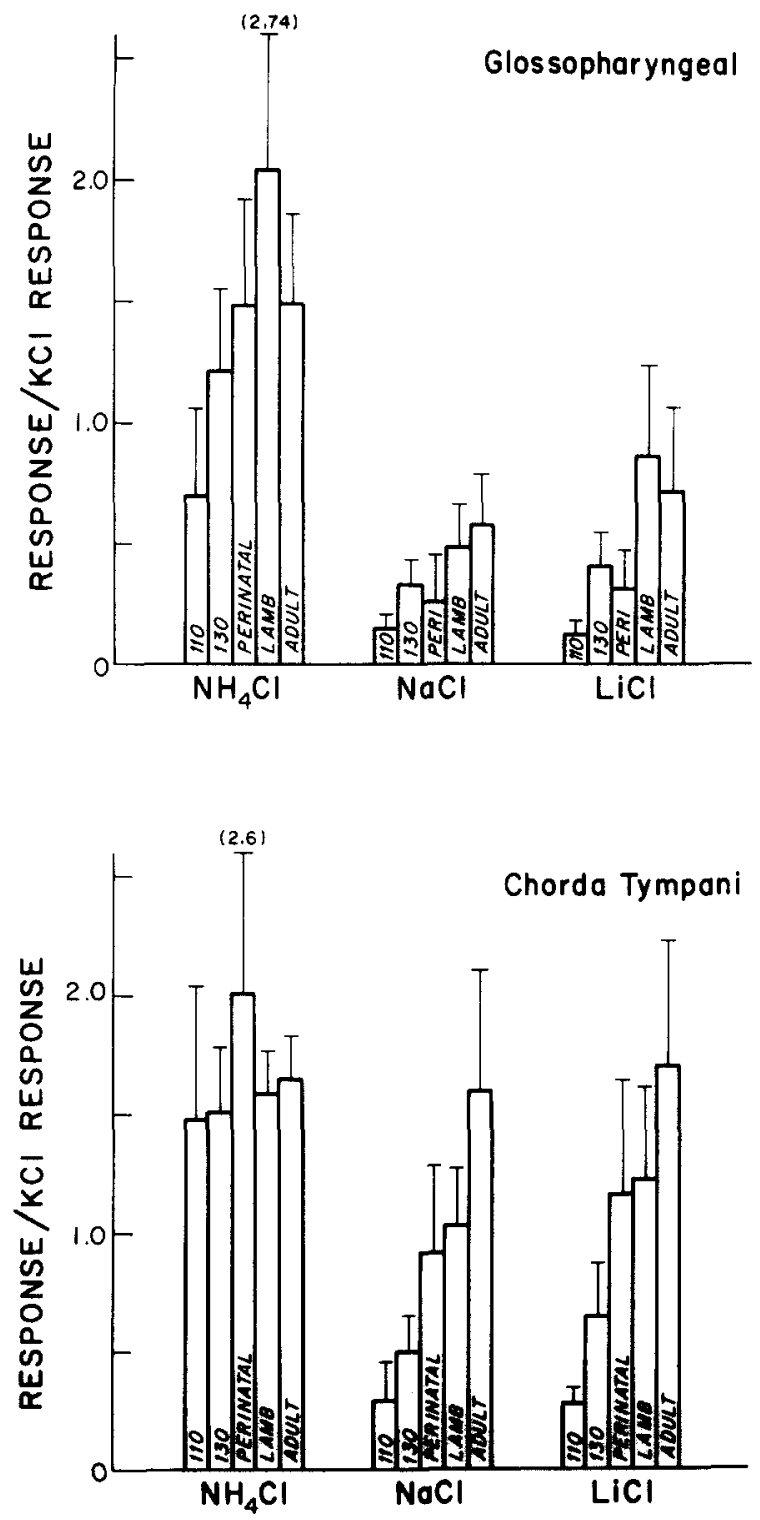

Fig. 4. Top: mean response ratios and standard deviations for $\mathrm{NH}_{4} \mathrm{Cl} . \mathrm{NaCl}$ and $\mathrm{LiCl}$, relative to $\mathrm{KCl}$, recorded from the glossopharyngeal nerve in fetuses (110 and 130 days of gestation, and perinatal), lambs and adults. For each salt, a response equal in magnitude to that elicited by $\mathrm{KCl}$ yields a ratio of 1.00 . Using $\mathrm{KCl}$ as a standard for posterior tongue responses emphasizes the relative increases in $\mathrm{NaCl}$ and $\mathrm{LiCl}$ responses during development. Bottom: data from a previous study on chorda tympani nerve responses ${ }^{25}$, reanalyzed relative to $\mathrm{KCl}$. $\mathrm{NaCl}$ and $\mathrm{LiCl}$ responses increase relative to $\mathrm{KCl}$, as when referred to the $\mathrm{NH}_{4} \mathrm{Cl}$ standard. The average $\mathrm{NH}_{4} \mathrm{Cl}$ response ratio for the perinatal group is greater than that for each of the other ages. but no other group differences are observed.

were for responses relative to the $\mathrm{NH}_{4} \mathrm{Cl}$ standard. Ratios for $\mathrm{NH}_{4} \mathrm{Cl} / \mathrm{KCl}$ changed also $\left(F_{4.41}=3.14, P\right.$ $=0.03$ ), although it is important to note that the $F$ value is small and variances were not equal among age groups. Pairwise comparisons demonstrated that only the high perinatal ratio differed from other age groups, including 110-day, 130-day and lamb (Fig. 4). Thus the overall change relates to the very high perinatal ratio.

Data in Figs. 3 and 4 illustrate that calculating responses relative to two standard chemicals can provide a more complete description of developmental changes. For example, significant postnatal changes emerged for $\mathrm{NH}_{4} \mathrm{Cl} / \mathrm{KCl}$ ratios that were not apparent with $\mathrm{KCl} / \mathrm{NH}_{4} \mathrm{Cl}$ ratios. In general, though, ratios calculated with both standards demonstrate increases in $\mathrm{NaCl}$ and $\mathrm{LiCl}$ relative responses, decreases in $\mathrm{KCl}$ and increases in $\mathrm{NH}_{4} \mathrm{Cl}$.

\section{Responses to citric and hydrochloric acids}

Average ratios for responses to two acids, relative to $\mathrm{NH}_{4} \mathrm{Cl}$, were analyzed (Fig. 5). Relative responses from the glossopharyngeal nerve for both citric and hydrochloric acid decreased during development $\left(F_{4,29}=3.34, P=0.025 ; F_{4.27}=2.99, P=\right.$ 0.04 , respectively). Pairwise comparisons demonstrated that for citric acid, the $\mathbf{1 1 0}$ day fetal group differed from perinatal, lamb and adult groups $(P<0.05)$. For $\mathrm{HCl}, 110$ day fetuses differed from lambs $(P=0.01)$, and perinatal animals differed from lambs and adults $(P<0.05)$. Therefore

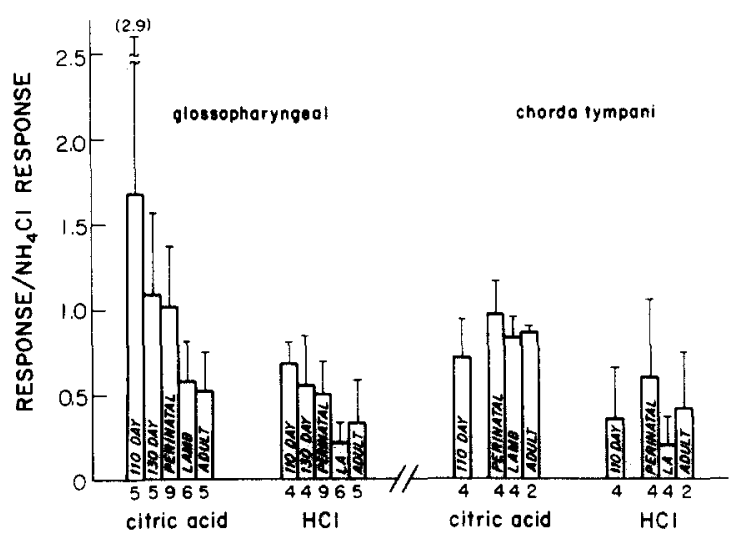

Fig. 5. Mean response ratios and standard deviations for citric acid and $\mathrm{HCl}$, relative to $\mathrm{NH}_{4} \mathrm{Cl}$, for fetuses (110 and 130 days of gestation, and perinatal), lambs and adults. Data from the glossopharyngeal and chorda tympani nerves are compared. Numerals under the histogram bars indicate numbers of animals in each age group for which acid responses were studied. Citric and hydrochloric acid response ratios from the glossopharyngeal nerve decreased developmentally; ratios from the chorda tympani did not change 


\section{0 doy}

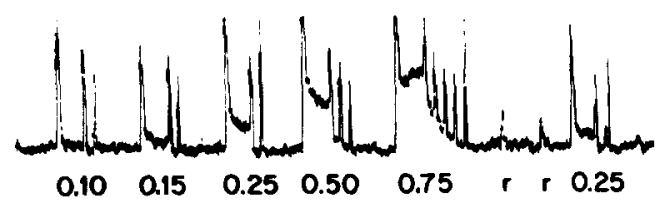

\section{Perinatal}

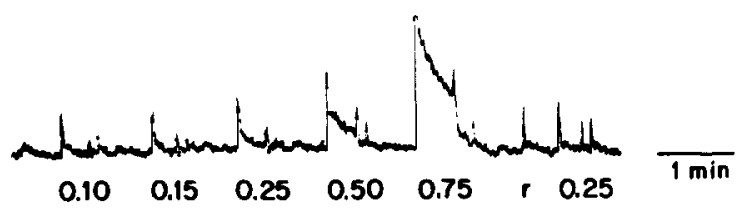

Lamb

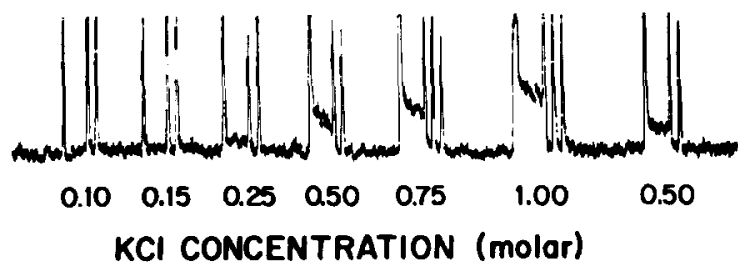

Fig. 6. Integrated records of multifiber responses from the glossopharyngeal nerve to a concentration range of $\mathrm{KCl}$ in animals from 3 age groups (110-day fetus, perinatal fetus at term, and lamb). Additional rinse applications are denoted beneath the records as ' $r$ '. At all ages 0.10 and $0.15 \mathrm{M} \mathrm{KCl}$ elicited relatively small response magnitudes and responses were still increasing at $0.75 \mathrm{M}$.

changes in citric acid ratios take place prenatally, whereas for $\mathrm{HCl}$, changes are pre- and postnatal.

Chorda tympani nerve responses to citric and hydrochloric acids were studied in fewer animals (Fig. 5); however, data indicate that there are no developmental changes in acid responses recorded from anterior tongue (citric acid: $F_{3,13}=1.38, P=$ $\left.0.31 ; \mathrm{HCl}: F_{3,13}=0.99, P=0.43\right)$. Thus anterior and posterior tongue taste buds apparently respond differently to these acids during development.

\section{Response-concentration functions for salts}

Responses to $0.10-0.75 \mathrm{M} \mathrm{KCl}$ and $\mathrm{NH}_{4} \mathrm{Cl}$ were studied at different ages. In all age groups, responses to $\mathrm{KCl}$ were of small magnitude at 0.10 and $0.15 \mathrm{M}$, and were still increasing in magnitude at $0.75 \mathrm{M}$ (Fig. 6). Although $1.00 \mathrm{M} \mathrm{KCl}$ was not applied to the tongue frequently, when used as a stimulus it elicited a larger response than $0.75 \mathrm{M}$ (Fig. 6). To learn whether the general shapes of these functions changed during development, data were plotted on linear and semilog graphs (Fig. 7A and B). Study of these functions with repeated measures of analysis of variance (Fig. 7A) indicated that the curves were parallel across age groups $\left(F_{4,12}=1.59, P=0.12\right)$. When slopes of the semilog functions (Fig. 7B) were compared with analysis of covariance, all 5 were parallel $\left(F_{4,127}=0.37, P=0.48\right)$. Therefore, for any given change in concentration, there is a proportionate change in response at all ages.

$\mathrm{NH}_{4} \mathrm{Cl}$ response-concentration functions were similar to those for $\mathrm{KCl}$ in two ways. Small response magnitudes were obtained at 0.10 and $0.15 \mathrm{M}$, and responses were increasing still at $0.75 \mathrm{M}$ (Fig. 8). Data were available for all ages except adult, and the functions were plotted on linear and semilog graphs for analysis (Figs. 9A and B). Analysis of the data
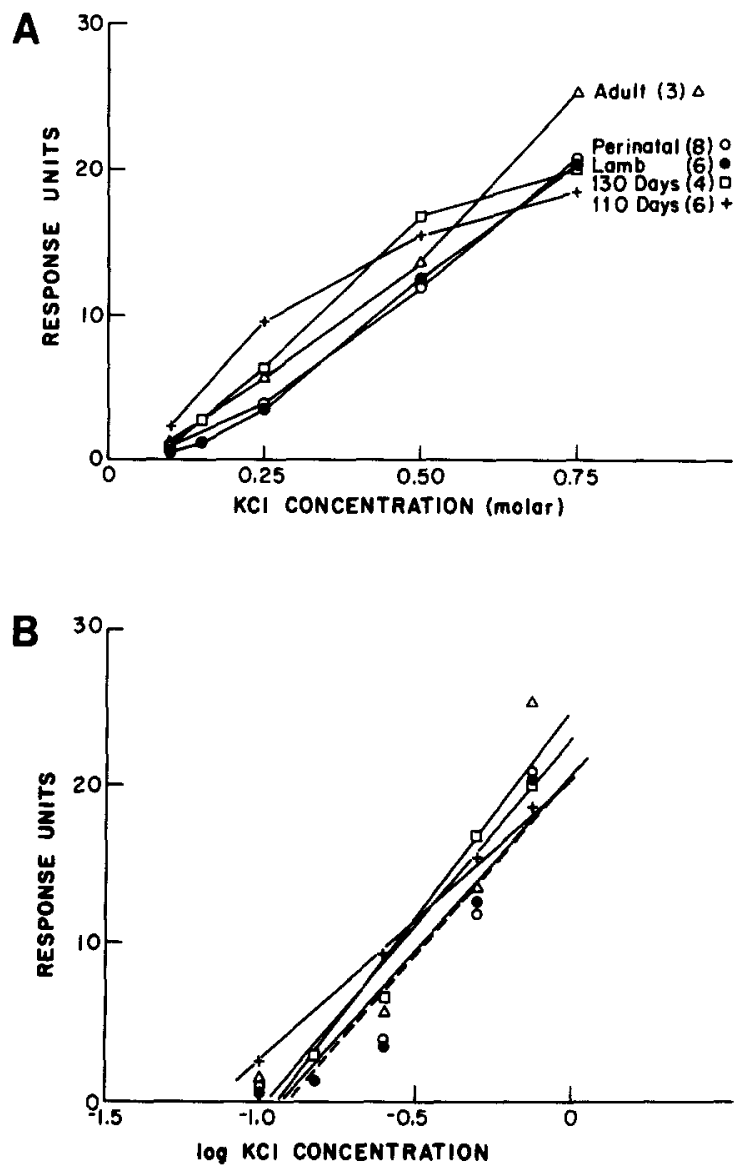

Fig. 7. Average responses to concentration series of $\mathrm{KCl}$ from 5 age groups. The number of response-concentration functions at each age is noted in parentheses in $A$. Linear plots are presented in $A$, and semilog plots in B for comparing slopes of the functions. The slopes of these functions do not change during development. 
110 day

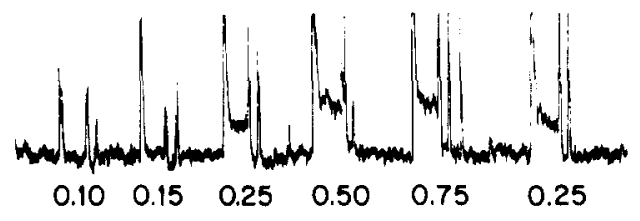

Perinatal

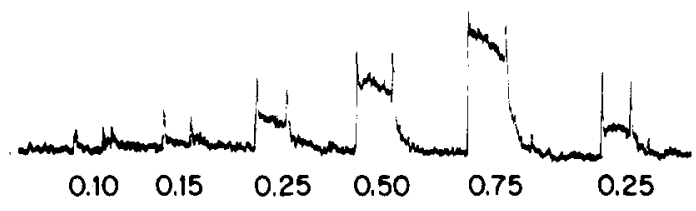

Lamb

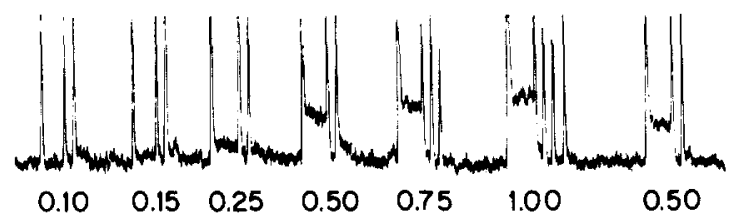

\section{$\mathrm{NH}_{4} \mathrm{Cl}$ CONCENTRATION (molar)}

Fig. 8. Integrated records of multifiber responses from the glossopharyngeal nerve to a concentration range of $\mathrm{NH}_{4} \mathrm{Cl}$ from animals in 3 age groups (110-day fetus, perinatal fetus at term, and lamb). At all ages response magnitudes to 0.10 and $0.15 \mathrm{M}$ are small, and responses are still increasing at $0.75 \mathrm{M}$.

with repeated measures of analysis of variance (Fig. 9A) indicated that slopes changed during development $\left(F_{9.66}=3.03, P=0.004\right)$. Also, analysis of covariance of the semilog functions (Fig. 9B) indicated that slopes were not parallel $\left(F_{3.115}=4.40, P=\right.$ $0.006)$ and multiple comparisons demonstrated that the slope at 110 days of gestation differed from all others $(P=0.003)$. Therefore concentration ranges of $\mathrm{NH}_{4} \mathrm{Cl}$ elicited different developmental responses. For a given change in concentration, responses in young fetuses did not increase as much as in older animals; the curves were flattened at higher concentrations.

The $\mathrm{NH}_{4} \mathrm{Cl}$ response-concentration data coupled with $\mathrm{NH}_{4} \mathrm{Cl} / \mathrm{KCl}$ ratio data in Fig. 4 indicate that not only is the $\mathrm{KCl}$ response decreasing developmentally, but also the $\mathrm{NH}_{4} \mathrm{Cl}$ response is increasing. Therefore the high $\mathrm{KCl} / \mathrm{NH}_{4} \mathrm{Cl}$ ratios in 110 -day fetuses (Fig. 3) reflect these parallel changes in responses to the two salts.
Functions for chorda tympani nerve responses to concentration ranges of $\mathrm{KCl}$ and $\mathrm{NH}_{4} \mathrm{Cl}$ were available for perinatal, lamb and adult age groups only25. Therefore we recorded from the chorda tympani nerve in 17 fetuses at 110 and 130 days of gestation. Linear plots for $\mathrm{KCl}$ and $\mathrm{NH}_{4} \mathrm{Cl}$ are presented in Fig. 10A and $\mathrm{B}$ for fetal, lamb and adult groups. Analysis of the linear functions with repeated measures of analysis of variance indicated no change in shapes of the curves for $\mathrm{KCl}\left(F_{9,45}=1.32, P=0.36\right)$, and slopes of semilog functions were parallel, also with analysis of covariance $\left(F_{3,81}=1.21, P=0.31\right)$.

$\mathrm{NH}_{4} \mathrm{Cl}$ response-concentration functions changed during development, however. Shapes of linear functions were not similar $\left(F_{12.61}=4.27, P=0.0001\right)$ nor
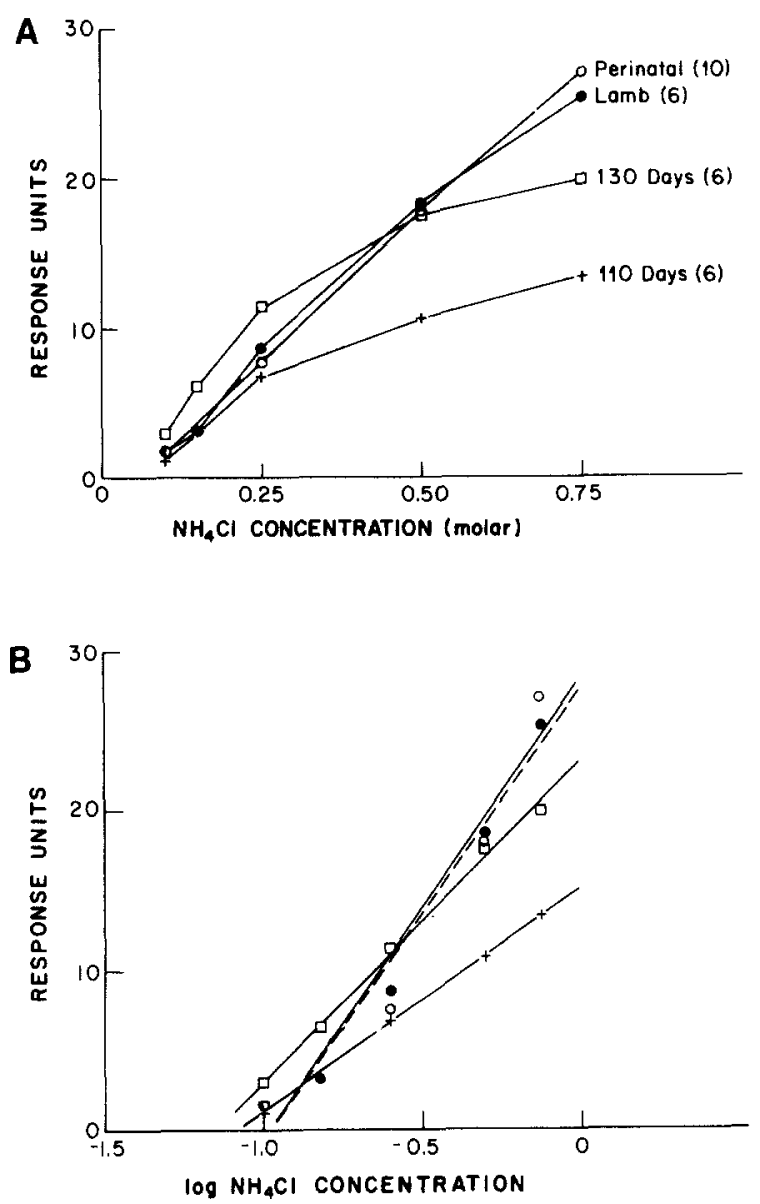

Fig. 9. Average responses to concentration series of $\mathrm{NH}_{4} \mathrm{Cl}$ in 4 . age groups. The number of response-concentration functions at each age is noted in parentheses in $A$. Linear plots are presented in $\mathrm{A}$, and semilog plots in $\mathrm{B}$ for comparing the slopes of the functions. The slope of the function for 110-day fetuses is significantly different from that for other age groups. 

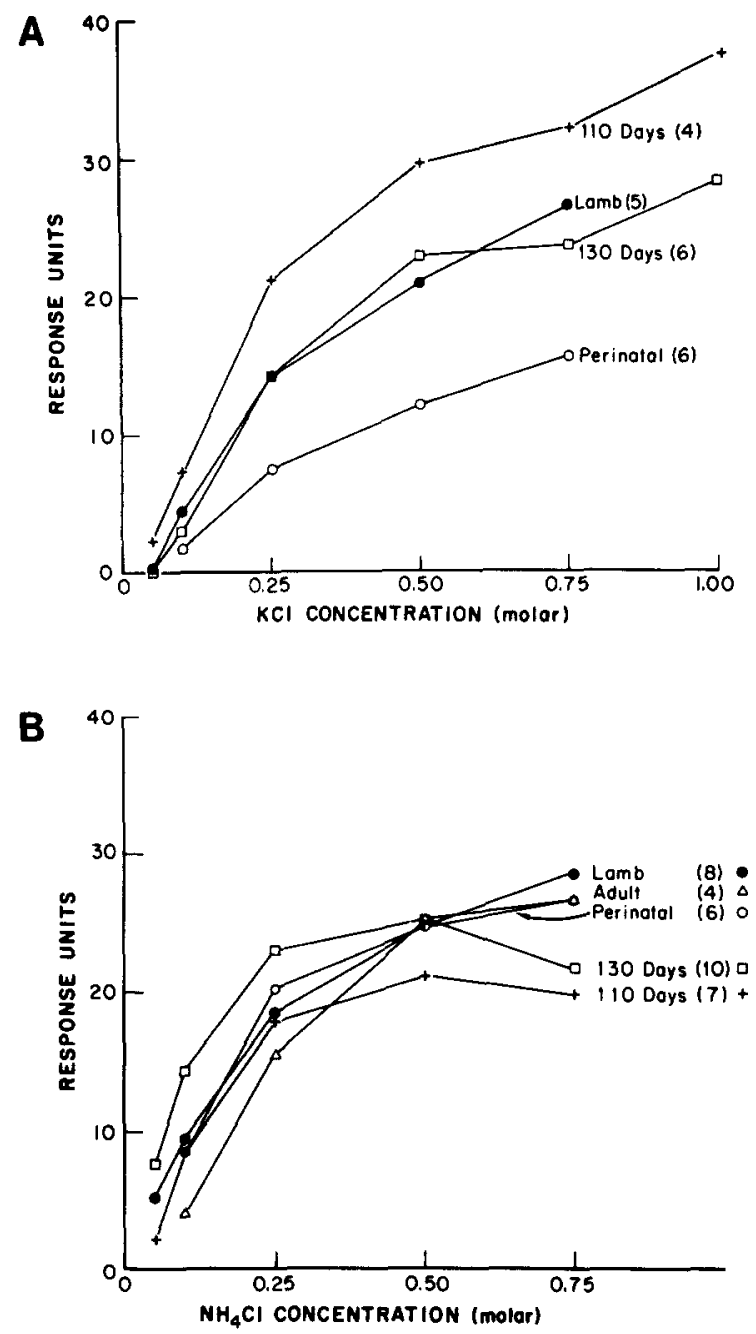

Fig. 10. Linear plots for average responses from the chorda tympani nerve to concentration series of $\mathrm{KCl}(\mathrm{A})$ and $\mathrm{NH}_{4} \mathrm{Cl}$ (B) in various age groups. The number of response-concentration functions at each age is noted in parentheses. The shapes of $\mathrm{NH}_{4} \mathrm{Cl}$ curves at 110 and 130 days of gestation are different from those at other ages. All $\mathrm{KCl}$ functions are similar in shape.

were slopes of semilog functions $\left(F_{4.117}=2.13, P=\right.$ $0.08)$. Slopes at 110 and 130 days of gestation were different from other ages $(P=0.007$ and 0.06 , respectively). As seen in Fig. 10B, at the highest $\mathrm{NH}_{4} \mathrm{Cl}$ concentration, responses in 110- and 130-day fetuses decreased in magnitude. For other age groups the response-concentration functions had not yet plateaued at $0.75 \mathrm{M}$. Thus, for both anterior and posterior tongue taste buds, there are developmental changes in responses to $\mathrm{NH}_{4} \mathrm{Cl}$ but not $\mathrm{KCl}$ over the concentration range studied.

\section{DISCUSSION}

Responses to salts and acids from taste buds in circumvallate papillae on the posterior tongue change during development in sheep. However, these changes differ from those for anterior tongue taste buds. For example, $\mathrm{KCl} / \mathrm{NH}_{4} \mathrm{Cl}$ ratios for glossopharyngeal nerve responses change substantially during prenatal development. $\mathrm{KCl}$ is nearly twice as effective as $\mathrm{NH}_{4} \mathrm{Cl}$ in young fetuses, but in adults it is much less effective. In contast, $\mathrm{KCl} / \mathrm{NH}_{4} \mathrm{Cl}$ ratios from the chorda tympani nerve alter only slightly during development ${ }^{25}$. Furthermore, whereas $\mathrm{NaCl}$ and $\mathrm{LiCl}$ relative responses increase by at least 5 times for anterior tongue, the increase is much less substantial for posterior tongue.

Responses to acid stimulation also differ between anterior and posterior tongue. There is a developmental decrease in the responses to citric and hydrochloric acids recorded from taste buds in circumvallate papillae. Acid responses from anterior tongue taste buds do not change during development.

Differences in salt and acid response ratios recorded from the peripheral innervation of taste buds on the anterior and posterior tongue demonstrate that developmental changes in taste responses cannot be attributed to some general epithelial characteristic. We have suggested that altering taste membrane composition accounts for changes in responses during development ${ }^{25}$. Since different changes take place for posterior and anterior tongue, there must be different proportions of membrane components maximally responsive to the several taste stimuli at various times in development.

Taste buds are added in circumvallate papillae on the back of the tongue prenatally and postnatally, just as they are in fungiform papillae on anterior tongue 9.10 . If the membrane composition of cells in newly-formed taste buds is different from that of cells in established taste buds, then altering taste responses would be predicted during development. Changing membrane composition characterizes other developing tissues ${ }^{19}$, and is therefore not unexpected in the taste system.

One possible change in membrane characteristics is addition of 'sites' or specific membrane components that interact with the various salts. For example, Beidler ${ }^{4}$ has presented data to demonstrate that 
$\mathrm{NaCl}$ and $\mathrm{LiCl}$ interact with one set of receptor sites on the taste membrane, whereas $\mathrm{NH}_{4} \mathrm{Cl}$ and $\mathrm{KCl}$ interact with two different, independent sets of sites with very different binding constants. It is known that $\mathrm{NaCl}$ and $\mathrm{LiCl}$ taste 'salty', whereas $\mathrm{NH}_{4} \mathrm{Cl}$ and $\mathrm{KCl}$ have bitter and sour taste components as well as salty 22,28. Developmental responses to monochloride salts recorded from the glossopharyngeal and chorda tympani nerves indicate a similarity between $\mathrm{NaCl}$ and $\mathrm{LiCl}$ as stimuli, and a difference among $\mathrm{NH}_{4} \mathrm{Cl}$, $\mathrm{KCl}$ and the other salts. Based on chorda tympani nerve responses, we had proposed that the two sets of sites for $\mathrm{NH}_{4} \mathrm{Cl}$ and $\mathrm{KCl}$ may form at different times in development, so that these salts initially interact with 'sour' receptor components and later with sour and 'salty' components25. Developmental changes in responses to salts and acids from the posterior tongue support this proposal; that is, early in development, $\mathrm{NH}_{4} \mathrm{Cl}, \mathrm{KCl}$, citric and hydrochloric acid are very effective stimuli. $\mathrm{NaCl}$ and $\mathrm{LiCl}$ are not very effective during early development and only later do they elicit substantial response magnitudes.

If receptor sites are added in type or number during development, then some change in responseconcentration functions is expected. For both $\mathrm{KCl}$ and $\mathrm{NH}_{4} \mathrm{Cl}$, inspection of the average curves in Figs. $7 \mathrm{~A}$ and $9 \mathrm{~A}$ illustrates that the glossopharyngeal nerve functions may asymptote at lower concentrations in 110- and 130-day fetuses than in older animals. A plateau at lower concentrations would be predicted if fewer sites were available for interaction with $\mathrm{K}$ or $\mathrm{NH}_{4}$ cations. However, when slopes of these functions were analyzed, an age-related difference was found for $\mathrm{NH}_{4} \mathrm{Cl}$ only. Similarly for chorda tympani nerve response-concentration functions, developmental changes were observed for $\mathrm{NH}_{4} \mathrm{Cl}$ only (Fig. 10B). However, $\mathrm{KCl}$ responses recorded from both nerves are still increasing in magnitude at $1.00 \mathrm{M}$ in all age groups, so use of higher concentrations to accurately define where the curves do plateau is necessary. With higher concentrations it might become apparent that fetal curves plateau at concentrations where postnatal functions continue to climb.

Other developmental data associate $\mathrm{NH}_{4} \mathrm{Cl}$ and $\mathrm{KCl}$ with acid stimuli. The pattern observed in glossopharyngeal nerve recordings for the developmental decrease in citric acid/ $\mathrm{NH}_{4} \mathrm{Cl}$ response ratios is very similar to that for $\mathrm{KCl} / \mathrm{NH}_{4} \mathrm{Cl}$ ratios (Figs. 3 and 5). In both instances the change is substantial and takes place prenatally only. In chorda tympani nerve recordings, there is only a slight developmental change in $\mathrm{KCl} / \mathrm{NH}_{4} \mathrm{Cl}$ response ratios, and citric acid $/ \mathrm{NH}_{4} \mathrm{Cl}$ ratios do not change at all. Therefore data from both anterior and posterior tongue suggest some similarity in citric acid and $\mathrm{KCl}$ responses, relative to $\mathrm{NH}_{4} \mathrm{Cl}$. This cannot be due to $\mathrm{pH}$ of the two stimuli, since at the concentrations we used, the $\mathrm{pH}$ for citric acid is 2.20 and that for $\mathrm{KCl}$ is 5.93 . The $\mathrm{pH}$ of the standard chemical, $0.5 \mathrm{M} \mathrm{NH}_{4} \mathrm{Cl}$, is 5.12 .

Single unit recordings could clarify whether integrated response changes during development relate to addition of specific fibers responding maximally to a particular stimulus, or to response frequency changes in an established set of fibers. In development of the rat taste system both sorts of changes occur ${ }^{17}$. But the question of receptor membrane alterations remains: are one or more receptor components being added, deleted or altered? For our multiunit data, analysis of response-concentration functions and ratio calculations using two standard, reference chemicals suggest that $\mathrm{NaCl}$ and $\mathrm{LiCl}$ components are probably added or 'strengthened' during development. If such components also interact to some extent with $\mathrm{NH}_{4} \mathrm{Cl}$ and $\mathrm{KCl}$, response changes to these salts should occur also, as observed.

\section{Development of neurophysiological taste responses and behavior}

Our data on peripheral nerve responses from taste buds on anterior ${ }^{25}$ and posterior tongue, and on central nervous system responses to anterior tongue stimulation ${ }^{11.24}$, predict that behavioral taste responses would change during prenatal and postnatal development. Neurophysiological data from rat peripheral ${ }^{13.16 .17}$ and central ${ }^{15}$ taste systems also predict that behavioral alterations would occur. Specifically, an early behavioral sensitivity to acids and to sour or bitter salts $\left(\mathrm{NH}_{4} \mathrm{Cl}\right.$ and $\left.\mathrm{KCl}\right)$ is expected. Only later would comparable sensitivity to $\mathrm{NaCl}$ be predicted. Indeed data from human studies suggest that infants are not very responsive to $\mathrm{NaCl}$ as a taste stimulus, whereas acids readily elicit responses ${ }^{2,20}$. In his paper on bovine taste responses, Bernard ${ }^{7}$ has referred to observations that calves do not discriminate between $0.09 \mathrm{M} \mathrm{NaCl}$ and water, whereas adult cows 
reject $\mathrm{NaCl}$ at this concentration. In preference tests, immature rats ingest much larger quantities of high $\mathrm{NaCl}$ concentrations than adults ${ }^{23}$. These collective observations provide evidence that developmental changes in electrophysiological salt responses apparently have behavioral correlates in postnatal animals.

\section{REFERENCES}

1 Appelberg, B., Species differences in the taste qualities mediated through the glossopharyngeal nerve, Acta physiol. scand., 44 (1958) 129-137.

2 Beauchamp, J. and Maller, O., The development of flavor preferences in humans. In M. R. Kare and O. Maller (Eds.), The Chemical Senses and Nutrition, Academic Press, 1977, pp. 292-315.

3 Beidler, L. M., Properties of chemoreceptors of tongue of rat, J. Neurophysiol., 16 (1953) 595-607.

4 Beidler, L. M., Taste receptor stimulation. In Progress in Biophysics and Biophysical Chemistry, Pergamon, 1961, pp. 107-151.

5 Beidler, L. M., Fishman, I. Y. and Hardiman, C. W., Species differences in taste response, Amer. J. Physiol., 181 (1955) 235-239.

6 Bell, F. R. and Kitchell, R. L., Taste reception in the goat, sheep and calf, J. Physiol. (Lond.), 183 (1966) 145-151.

7 Bernard, R. A., An electrophysiological study of taste reception in peripheral nerves of the calf, Amer. J. Physiol., 206 (1964) 827-835.

8 Bradley, R. M., Tongue topography. In L. M. Beidler (Ed.), Handbook of Sensory Physiology, Vol. IV, Chemical Senses, Part 2, Taste, Springer-Verlag, Berlin, 1970, pp. 1-30.

9 Bradley, R. M. and Mistretta, C. M., The morphological and functional development of fetal gustatory receptors. In N. Emmelin and Y. Zotterman (Eds.), Oral Physiology, Pergamon, Oxford, 1972, pp. 239-253.

10 Bradley, R. M. and Mistretta, C. M., The gustatory sense in foetal sheep during the last third of gestation, J. Physiol. (Lond.), 231 (1973) 271-282.

11 Bradley, R. M. and Mistretta, C. M., Developmental changes in neurophysiological taste response from the medulla in sheep, Brain Research, 191 (1980) 21-34.

12 Davies, R. O., Kare, M. R. and Kagan, R. H., Distribution of taste buds on fungiform and circumvallate papillae of bovine tongue, Anat. Rec., 195 (1979) 443-446.

13 Ferrell, M. F., Mistretta, C. M. and Bradley, R. M., Development of chorda tympani taste responses in rat, J. comp. Neurol., 198 (1981) 37-44.

14 Frank, M. and Pfaffmann, C., Taste nerve fibers: a random distribution of sensitivities to four tastes, Science, 164 (1969) 1183-1185.

15 Hill, D. L., Developmental changes in taste responses from rat solitary nucleus, Soc. Neurosci. Abstr., 8 (1982) 753.

16 Hill, D. L. and Almli, R., Ontogeny of chorda tympani

\section{ACKNOWLEDGEMENTS}

This research was supported by N.S.F. Grant BNS 80-15737 to C.M.M. and R.M.B., and by N.I.H., N.I.D.R. Research Career Development Award DE 00066 to C.M.M. We thank Dr. David L. Hill for critical comments on the manuscript.

nerve responses to gustatory stimuli in the rat, Brain Research, 197 (1980) 27-38.

17 Hill, D. L., Mistretta, C. M. and Bradley, R. M., Developmental changes in taste response characteristics of rat single chorda tympani fibers, J. Neurosci., 2 (1982) 782-790.

18 Iggo, A. and Leek, B. F., The afferent innervation of the tongue of the sheep. In T. Hayashi (Ed.), Olfaction and Taste, II, Pergamon Press, Oxford, 1967, pp. 493-507.

19 Kapitulnik, J., Tshershedsky, M. and Barenholz, Y., Fluidity of the rat liver microsomal membrane: increase at birth, Science, 206 (1979) 843-844.

20 Maller, O. and Desor, J., Effects of taste on ingestion by human newborns. In J. F. Bosma (Ed.), Fourth Symposium on Oral Sensation and Perception, DHEW Publ. No. 73546, 1973, pp. 279-291.

21 Marowitz, L. A. and Halpern, B. P., Gustatory neural response of the chorda tympani to lick-duration stimuli, Chem. Senses Flavor, 2 (1977) 457-485.

22 McBurney, D. H. and Shick, T. R., Taste and water taste of twenty-six compounds for man, Percept. Psychophysiol., 10 (1971) 249-252.

23 Midkiff, E. E. and Bernstein, I. L., The influence of age and experience on salt preference of the rat, Develop. Psychobiol., 16 (1983) 385-394.

24 Mistretta, C. M. and Bradley, R. M., Taste responses in sheep medulla: changes during development, Science, 202 (1978) 535-537.

25 Mistretta, C. M. and Bradley, R. M., Neural basis of developing salt taste sensation: response changes in fetal, postnatal and adult sheep, J. comp. Neurol., 215 (1983) 199-210.

26 Oakley, B., Altered temperature and taste responses from cross-regenerated nerves in the rat's tongue, J. Physiol. (Lond.), 188 (1967) 353-371.

27 Smith, D. V. and Bealer, S. L., Sensitivity of the rat gustatory system to the rate of stimulus onset, Physiol. Behav., 15 (1975) 303-314.

28 Smith, D. V. and McBurney, D. H., Gustatory cross-adaptation: does a single mechanism code the salty taste? J. exp. Psychol., 80 (1969) 101-105.

29 Yamada, K., Gustatory and thermal responses in the glossopharyngeal nerve of the rat, Jap. J. Physiol., 16 (1966) 599-611.

30 Yamada, K., Gustatory and thermal responses in the glossopharyngeal nerve of the rabbit and cat, Jap. J. Physiol., 17 (1967) 94-110. 